cal profession to agree among themselves. In all disputes the stronger party shonld rule the weaker. Let us do the same; let each county in Great Britain and Ireland send so many deputies, and let them meet in London, make propositions, and let it be decided by the deputies in each county, of course representing the will of the strong. This is the only way $I$ see of settling the point.

Cardiff, 1849.

I beg to remain, Sir, yours obediently, Edward Wilitams.

\section{ALUM IN HOOPING-COUGH.} To the Editor of The LaNcet.

Str,-I beg to call the attention of the profession to the superior efficacy of alum, as a remedy for hooping-congh. I am well aware that it is already known to many eminent practitioners; but it is far from being so extensively used as it deserves to be.

I could enumerate many cases in which $I$ have administered alum, with almost uniform success. After the first stage of the disease is over, and the convulsive cough is established, my general practice is to prescribe powdered alum, in doses of from two to ten grains, (proportioned to the age of the patient,) three times a day, and the result, with very rare exceptions, is, that the distressing whoop disappears in about two days after the first administration of the medicine, and the disease is reduced to what it was during the first stage: after another week or two, all the symptoms vanish. I do not mean to say that it is a specific for the disease, but it approaches that character, in regard to hooping-cough, as nearly as quinine does, in regard to intermittents. As the pathology of the disease is obscure, it must be difficult to explain the modus operandi of the medicine. I believe it acts as a nervine tonic, and so removes the spinal excitability existing at the origin of the nerves of respiration. This opinion $I$ am the more inclined to, as I have seen the good effects of alum in analogous diseases. This may be a mere hypothesis, but I am one of those who consider hypotheses useful, when they do not go against practical experience, as they serve to arrange our knowledge of facts. Kepler's hypotheses prepared the way for the theories of Newton, as the Newtonian hypothesis of light paved the way for the theory of Young.

I remain, yours most respectfully,

Queen-square, Bristol, 1849. David Davies.

\section{IODINE IN THE URINE.}

To the Editor of The Lavoet.

SIR,-I perceive in THE LaNCET of the 21st plt. a query from a correspondent who signs "X. Y. Z." (Leamington), respecting the state in which iodine exists in the urine. He seems to be unaware that the existence of iodine in the urine in cases where the patient is taking either the element or any of the salts of its hydracid, is a very familiar fact. If "X.Y.Z." will consult the classical work of my friend Dr. Cogswell on iodine, published in 1837, he will find many illustrations of the facility with which iodine passes into the urine.

But my chief object, in sending this note to you, is to make an observation on the concluding portion of his letter. $\mathrm{He}$ says, "Does this urine contain free iodine of potassium, or is there any decomposition in the passage of this medicine through the system, and does the iodine exist in combination with any of the salts of the urine?" The question is a very pertinent one. I beg to reply as follows :-1st. The iodine cannot be free in the urine in any case, because we always find the agency of an acid necessary to liberate it. Nitric or sulphuric acid commonly used for this purpose would either decompose free hydriodic acid or the hydriodate of potass, or any other salt of the hydracid. In the case of the salts,setting free the hydriodic acid and decomposing it afterwards, by giving oxygen to its hydrogen, and causing the formation of sulphurous acid or peroxide of azote. But the existence of free hydriodic acid in the urine is, I think, out of the question, considering the bases in this complicated fluid with which so strong an acid might combine. In my work on the physiological and medicinal properties of bromine and its compounds, and on the analogies between these bodies and the corresponding ones of the chlorine and iodine groups, (Edinburgh Medical and Chirurgical Journal, July and October, 1842,) I endeavoured to show that salts of chlorine, bromine, and iodine are active nearly in the proportions of their solubility and facility of decomposition. And $I$ have inserted the following note in my work on scrofula (p. 242):-

2. "We have proved of the whole class of compounds, of chlorine, bromine, and iodine, that their activity is in pro- portion to their solubility and facility of decomposition. We have, moreover, shown experimentally that many of them are partially decomposed in the body. The elements liberated in the system in the nascent form would thus be much more active. In all probability, a great portion of the action of a substance is thus owing to a series of combinations and decompositions which it affects and undergoes in the system giving rise to numerous molccular changes."

That is, - I believe hydriodic acid may be separated in the first instance from its base, when introduced into the system as a salt, and re-appear in a state of combination in the urine.-I am, Sir, your obedient servant,

Newcastle-on-Tyne, May, 1849 . R. M. Glover, M.D.

\section{CHEMICO-GELATINOUS INJECTION FOR ANATOMICAL PREPARATIONS.}

\section{To the Editor of The Lancet.}

Sir,-Having received several letters addressed to me by your readers from several parts of the country, requiring further information on the subject of my paper on the "Chemico-gelatinous Injection," published in THE LANCET of Maroh 17th, I shall feel much obliged by the insertion of the following as the answer to them, and an addendum to my paper. I am, Sir, your obedient servant,

Gray's-inn-road, April, 1849 .

Henry Goadby.

When size injection is to be employed, coloured either with vermillion or the chromate of lead, the animal should be previously prepared by bleeding, to empty the vessels; for if they be filled with coagulated blood, it is quite impossible to transmit even size, to say nothing of the colouring matter. Hence the difficulty of procuring good injections of the human subject.

But with the "chemico-gelatinous" injection no such preparation is necessary; and success should always be certain, for the potash liquefies the blood, while constant and long-con. tinued pressure by the syringe drives it through the parietes of the vessels into the cellular tissue. The large quantity of infiltrated blood - the invariable concomitant of my processcharacterizes this from all other modes of injecting, and is a distinctive feature of these preparations.

I find that a very superior preparation of gelatine is now on sale at the grocers' shops, nearly equal in appearance to isinglass. From its apparent purity, I am led to infer that a less quantity of it would suffice for the number of fluid ounces of the other ingredients indicated in the paper alluded to.

The only preparations of gelatine extant when I made the experiments recorded in my paper, contained a large quantity of dirty, insoluble gluten, from which defect I venture to assume the French gelatine is free.

\section{THE COLLEGE AND ITS MEMBERS; THE PRO- JECTED NEW COLLEGE (!) AND THE INTRIGUES OF THE INSTITUTE.}

To the Editor of THE LANCET.

SIR,-The fellows of the College of Surgeons, particularly those who have become so by purchase and examination, are no doubt infinitely indebted to Mr. Guthrie for the lucid exposition of their positive and relative merits contained in THz LANOET.

The original list, he tells us, was made without strict adherence to any principle that he is aware of; though how this assertion is to be reconciled with the "Statement" published by the Council on that subject, he has omitted to inform us. As to the others who have been admitted by examination, his notice of them is not very flattering, certainly. One is tempted to ask-If such is the estimate formed by the exa. miners of the successful candidates, what must be thought of the rejected? These, however, are questions which,whatever profitable meditation they may suggest to those whom they concern, it is not my present purpose to discuss. My business is with another aspect of the affair, and one to which I beg leave to draw the attention of my brother members.

Worthless as the distinction is now declared to be, it is still attempted, by means of this said fellowship, not only to degrade the members in collegiate rank, but also to deprive them of their legal privileges.

I have before me a Report, emanating from the Council of the National Institute, from which it appears that the president and other officers of the College of Surgeons have for some time been engaged, in concert with other parties, in the laudable endeavour to induce the legislature to repeat all those 